\title{
0 Papel do Pó de Ferro no Mecanismo de Deposição de Eletrodos Revestidos
}

\author{
Víctor Augusto Nascimento Magalhães ${ }^{1}$, Wilian da Silva Labiapari², Vladimir Ponomarev ${ }^{3}$, Américo Scotti $^{3}$ \\ 1 Universidade Federal dos Vales do Jequitinhonha e Mucuri - UFVJM, Diamantina, MG, Brasil. \\ 2 Aperam, Timóteo, MG, Brasil. \\ 3 Universidade Federal de Uberlândia - UFU, Uberlândia, MG, Brasil.
}

Recebido: 23 Set., 2014

Aprovado: 09 Fev., 2015

E-mails:

victor.nascimento@ict.ufvjm.edu.br (VANM), wilian.labiapari@aperam.com (WSL), ponomarev@mecanica.ufu.br (VP), ascotti@mecanica.ufu.br (AS)
Este é um artigo publicado em acesso aberto (Open Access) sob a licença Creative Commons Attribution Non-Commercia que permite uso, distribuiçăo e reproduçăo em qualq'uer meio, sem restriçōes desde que sem fins comerciais e que 0 trabalho original seja corretamente citado.
Resumo: A principal motivação deste trabalho foi a procura da resposta para o dilema entre que as maiores taxas de produção de eletrodos revestidos com pó de ferro se devem às suas capacidade de trabalhar com maior corrente ou à uma maior eficiência de fusão metálica do ferro adicionado na forma de pó. Um estudo neste sentido foi feito utilizando-se três eletrodos comerciais, cuja principal distinção referia-se ao teor de pó de ferro no revestimento. Os eletrodos foram caracterizados em relação às suas dimensões, densidade e composição (via MEV-EDS) do revestimento. Utilizando-se dois níveis de corrente, foram avaliadas as taxas de fusão e deposição e a geometria do cordão na confecção de filetes na posição plana (junta em ângulo). Pelos resultados, verificou-se que, independentemente da intensidade da corrente, as taxas de fusão e deposição são maiores no sentido crescente da maior concentração de pó de ferro no revestimento. Ficou demonstrado que o mecanismo gerador de maiores taxas de deposição e fusão se deve à menor energia requerida para fundir o ferro do revestimento em forma de pó que o contido na alma metálica. A maior capacidade nominal de condução corrente proporcionada pelo eletrodo com pó de ferro é uma razão secundária.

Palavras-chave: Eletrodo revestido; Pó de ferro; Taxa de fusão.

\section{The Role of Iron Powder on the Deposition Mechanism in Coated Electrode}

\begin{abstract}
The main motivation for this work was a search for an answer to the dilemma of which higher deposition rates of metal powder based coating electrodes are due to either their capacity of working at higher currents or a higher fusion efficiency of the metal powder. This study was developed using three commercial coated electrodes, which main distinction was the iron powder content in their coatings. The electrodes were characterized in relation to their dimensions, coating densities and compositions (via MEV-EDS). Using two current levels, fusion and deposition rates and bead geometry from fillet carried out in flat position (T-joint) were assessed. From the results, fusion and deposition are greater when the iron concentration in the coating are higher, regardless the current level. It was demonstrated that the mechanism for reaching higher deposition rates is related to a lower required energy to melt the iron in powder than in solid state. A higher nominal carrying current capacity acquired by the electrode with iron powder is a secondary reason.
\end{abstract}

Key-words: Shielded Metal Arc Welding; Coated electrode; Iron poder; Deposition rate.

\section{Introdução}

Segundo Liu [1], na metade do século 20 a indústria de bens de capital percebeu o impacto revolucionário da introdução do processo de soldagem, mais especificamente a soldagem com eletrodo revestido. Rapidamente, as indústrias passaram a demandar melhor qualidade da solda, estabilidade de processo e versatilidades de materiais. No mesmo sentido, Van Den Berg e Haverhals [2] acrescentam que as demandas na utilização de eletrodos revestidos em juntas não eram, contudo, só por boas propriedades mecânicas, mas também pela economia de consumíveis. Em resposta, segundo Liu [1], três grandes conquistas ocorreram na década de 50. O primeiro foi o desenvolvimento do eletrodo tubular, seguido pelos eletrodos de baixo hidrogênio e, por fim, os eletrodos com pó de ferro, ditos de alta eficiência. Van Den Berg e Haverhals [2] reforçam esta citação, mencionando que o período após a segunda grande guerra mundial até 1980 foi marcado 
pela introdução maciça no mercado dos eletrodos básicos de baixo hidrogênio e com pó de ferro. Neste período, o maior apelo era pela redução de custo e aumento de produtividade.

Subramanian [3] descreve que inicialmente o revestimento dos eletrodos era fino e sua principal função era a estabilização do arco. Posteriormente, a adição de pós metálicos de ferros ligas tornou-os mais funcionais, de maior produtividade e desempenho. A menção de Van Den Berg e Haverhals [2] acrescenta que os eletrodos revestidos de alta deposição podem trazer grandes benefícios; além do ganho na produtividade, o custo da solda pode ser reduzido em até 50\%. Há ainda, segundo Van Den Berg e Haverhals [2], um ganho adicional pela redução das distorções térmicas, em função de uma poça relativamente mais fria, diminuindo a necessidade de etapas como o alívio de tensões.

A rapidez com que se dá a fusão do eletrodo é fundamental para economia de tempo e dinheiro num processo de soldagem. A energia para fundir os eletrodos em processos a arco, entre eles o eletrodo revestido, é dependente do valor da corrente. O aquecimento se dá na região de acoplamento do arco com o eletrodo assistido pelo efeito Joule ao longo dele. No caso do eletrodo revestido, calor é necessário para fundir tanto a alma como o revestimento. A deposição líquida desse material fundido (excluindo perdas por respingos, escória, fumos, etc.) por unidade de tempo é que caracteriza a formação do cordão. Por isto, a taxa de deposição líquida é o alvo a se aumentar. Entretanto, o simples aumento da corrente como meio de aumentar a taxa de fusão (consequentemente a taxa de deposição) dos eletrodos revestidos é limitado. Uma corrente muito alta para um dado diâmetro de eletrodo pode, por aquecimento ao longo de seu comprimento, danificar (inutilizar) o revestimento. Assim, uma forma de ganhar em produção seria aumentar o diâmetro da alma, juntamente com o correspondente aumento de corrente, uma vez que a corrente é proporcional ao diâmetro da alma. Mas a prática mostra um limite de 6,0 mm no diâmetro. Outra solução seria adicionar material através do revestimento. Por exemplo, Cruz-Crespo et al. [4], em um trabalho sobre a influência da composição do revestimento na taxa de fusão de eletrodos revestido para revestimento duro, mostraram que o aumento do teor de calcita faz crescer esta taxa. Mas, com este propósito, o pó de ferro tem sido mais usado e mostrado ser mais efetivo (de maior sensibilidade). Porém, a simples adição, e não substituição, de pós metálicos no revestimento acarreta em fazer revestimentos mais espessos. Entretanto, conforme o revestimento fica mais espesso, problemas podem começar a ocorrer, como [2]:

- O metal fundido do eletrodo não é homogeneamente envolvido pelo fluxo fundido, sendo um agente de detrimento da qualidade da solda;

- A estabilidade do processo se reduz, acompanhada de um aumento de respingos;

- Surgimento de mordeduras, ocorrendo quando a solda não é na posição plana, como uma consequência do aumento da poça de fusão;

- Grandes crateras, aumentando o risco de trincas;

- Porosidade nas crateras;

- Aumento da distorção pelo aumento da energia imposta;

- Maior fadiga do soldador, suportando o efeito combinado de peso do eletrodo, dos cabos e porta-eletrodo, além do estresse por ter que controlar uma maior poça de fusão;

- A fadiga do soldador pode ainda conduzir a uma variação do comprimento do arco, levando a uma perda de qualidade do cordão de solda;

- Escorrimento de metal em soldagem na posição vertical.

Os fabricantes dos eletrodos são cientes dos fatos acima e sabem balancear os benefícios e efeitos colaterais da adição de material metálico no revestimento. Assim, os eletrodos revestidos de alta eficiência contêm pós-metálicos em quantidades suficientes para aumentar os seus rendimentos de deposição sem agravar em demasia os efeitos colaterais negativos. É importante destacar que tradicionalmente rendimento de deposição para eletrodos revestidos é referenciado como valor nominal, ou seja, trata da relação entre a quantidade de metal depositado e o massa de alma fundida, portanto, desconsiderando a massa do revestimento. A diferença desse parâmetro para o que seria o rendimento de deposição real tem sido notificada em vários livros (como a relação entre a quantidade de metal 
depositado e o peso do eletrodo fundido como um todo, portanto, considerando a massa do revestimento), mas pode ser achada de forma detalhada na publicações de Scotti e Dutra [5] and Ponomarev et al. [6]. Neste contexto, os valores de rendimento nominal de deposição pode chegar até $250 \%$, mas requer um eletrodo com revestimento extremamente espesso [2], o que torna mais difícil não apenas o processo de soldagem (o uso do eletrodo), mas também o processo de fabricação/extrusão dele [3].

Segundo Subramanian [3], o pó de ferro no revestimento tem fator predominante para o aumento da taxa de deposição quando comparada com os outros elementos de liga presentes. Mas é importante se deve lembrar de que a adição ferro na solda não se faz apenas através da adição da forma metálica como elemento comercialmente puro no revestimento. Segundo Grong et al. [7], ferros ligas, como Fe-Si, podem ser utilizados no processo de fabricação dos eletrodos, tornando-os mais baratos do que se utilizar ligas puras para se conseguir um incremento extra de ferro depositado (no caso o Si age como desoxidante).

Os eletrodos de alta eficiência a base de pó de ferro, além da maior deposição metálica, também se caracterizam pela possibilidade de utilização de correntes mais elevadas [2], já que a presença de pó de ferro, segundo Subramanian [3], aumenta a condutividade elétrica. Esta última afirmação é, porém, motivo de controvérsias. Existem outras citações na literatura que se perpetuaram e também demandam mais esclarecimentos. Por exemplo, de acordo com Subramanian [3], "o sobreaquecimento da poça de fusão é controlado pela capacidade do revestimento em resfriá-la". Muitas características associadas aos pós-metálicos em eletrodos rutílicos, tais como, redução da tendência à mordedura, estabilidade do arco e bom acabamento, etc, [2,3] merecem demonstrações por meios mais científicos. Isto pois, tendo conhecimento dos mecanismos de atuação do pó de ferro, outros processos que se utilizam de fluxo também podem ser melhor aproveitados.

De qualquer forma, na prática é sabido que eletrodos de alta eficiência (com pó de ferro) oferecem maior taxa de deposição do que eletrodos ditos normais (sem pó de ferro) e tem uma maior capacidade de condução de corrente (valores de corrente possíveis de serem conduzidos pelo eletrodo sem perder a estabilidade do arco ou danificar o revestimento). Este fato é evidente nas recomendações de faixa de corrente que todos fabricantes apresentam para seus produtos. Como regra empírica, a faixa de corrente de um eletrodo revestido é calculada como I = 30 a 40 vezes o diâmetro nominal do eletrodo (da alma, em $\mathrm{mm}$ ), valores acrescidos em, aproximadamente, $10 \%$ para casos de eletrodos com pó de ferro. Entretanto, não se encontra na literatura uma resposta para a seguinte questão: é o fato de se permitir trabalhar com maiores correntes (maior capacidade nominal de conduzir corrente) ou o de ter pó de ferro em seu revestimento o que rege o efeito da maior taxa de deposição dos eletrodos revestidos? A esta dúvida se atribui a hipótese de que se for a maior corrente a variável predominante, a solução mais simples poderia ser aumentar o diâmetro da alma do eletrodo.

Desta forma, o objetivo do presente trabalho foi estudar de forma mais consistente o papel do pó de ferro sobre o mecanismo de fusão e deposição de eletrodos revestidos, visando responder (e esclarecer) a questão acima.

\section{Materiais e Métodos}

Para avaliar a influência do pó de ferro na taxa de deposição, foram utilizados três tipos de eletrodos comerciais (todos com $350 \mathrm{~mm}$ de comprimento e 3,25 mm de diâmetro nominal), com diferentes teores de pó de ferro no revestimento, conforme as especificações da AWS A5.1/A5.1M:2012 (Specification for Carbon Steel Electrodes for Shielded Metal Arc Welding):

- E7016 - Eletrodo com revestimento básico sem pó de ferro (faixa de corrente recomendada pelo fabricante de 80 a 130 A);

- E7018 - Eletrodo com revestimento básico e adição de pó de ferro (faixa de corrente recomendada pelo fabricante de 90 a $150 \mathrm{~A}$ );

- E7024 - Eletrodo com revestimento rutílico e com alto teor de pó de ferro (faixa de corrente recomendada pelo fabricante de 130 a 170 A).

Soldagens foram feitas com cada eletrodo em dois níveis de corrente, nominalmente $115 \mathrm{~A}$ e $145 \mathrm{~A}$, dentro dos limites especificados pelos fabricantes, exceto para o ER7016, cuja corrente empregada ultrapassa o limite máximo $(130$ A) recomendado, mas foi utilizada para fins de comparação. 
Como placas de teste, foram utilizadas chapas de aço carbono de dimensão de $200 \times 38 \times 6,35 \mathrm{~mm}$. Estas chapas foram esmerilhadas para remoção de óxidos superficiais e, em seguida, ponteadas, compondo uma junta em ângulo para deposição do cordão de solda do tipo filete na posição plana, conforme Figura 1a. A escolha deste tipo de junta foi feita em função de ser uma aplicação comum de eletrodos revestidos. Para se eliminar a influência do soldador, todas as soldas foram executadas por um sistema automatizado para soldar com eletrodo revestido, ilustrado na Figura 1b, que mantém o comprimento do arco pelo controle do avanço de um fuso partindo de uma tensão de referência pré-estabelecida para o comprimento de arco desejável. A diferença entre a tensão de arco e a tensão de referência faz o ajuste do comprimento de arco funcionar. Procurou-se sempre manter o arco bem curto (variando-se a tensão de referência) para cada combinação de eletrodo e corrente (como feito por um soldador), soldando-se com o eletrodo puxando a um ângulo de aproximadamente $15^{\circ}$ graus, sem tecimento.

Para comparar o efeito do pó de ferro em cada tipo de eletrodo, principalmente sobre aspectos geométricos, procurou-se manter o mesmo volume de poça em cada soldagem. Isto pôde ser feito soldando-se com os 3 tipos de eletrodo em uma mesma velocidade e corrente de soldagem. Após calcular a taxa de deposição, tomou-se como referência o eletrodo que deu a maior taxa. Assim, os eletrodos que proporcionaram menores taxas, tiverem redução ponderada nas suas velocidades de soldagem como forma de manter o mais próximo possível a quantidade de material depositado por unidade de comprimento de solda (ou volume da poça) do conseguido pelo eletrodo de referência. A taxa de deposição (medida em g/min, pela diferença de peso da chapa antes e após o depósito, livre de escória e respingos, e o tempo de arco aberto), por sua vez, é diferenciada da taxa de fusão (medida pela diferença de peso do eletrodo antes e após a soldagem e o tempo de arco aberto), devido a perdas principalmente na forma de respingos, escória e fumos. Mas no caso do pó de ferro no revestimento, é de se esperar que grande parte dele se agregue ao cordão e não se perca como escória. Sendo assim, inicialmente soldou-se os 3 eletrodos com uma corrente de $145 \mathrm{~A}$ à uma velocidade de 21,36 cm/min. Esta velocidade foi inicialmente escolhida por proporcionar um cordão de bom aspecto visual. Em seguida, calcularam-se os parâmetros relacionados com a deposição (Tabela 1). Como era de se esperar, a quantidade de material depositada por cada eletrodo por unidade de tempo ou de comprimento de solda foi diferente. Por apresentar a maior taxa, a velocidade para o E7024 foi mantida em $21,36 \mathrm{~cm} / \mathrm{min}$ e as para os outros dois eletrodos foram corrigidas. O mesmo procedimento foi aplicado para a corrente de $115 \mathrm{~A}$. A Tabela 2 sumariza os resultados finais para cada combinação eletrodo-corrente.

Para melhor detalhamento e entendimento, diversas características dos eletrodos utilizados foram avaliadas. Todos os eletrodos foram padronizados em $350 \mathrm{~mm}$ de comprimento (os que eram maiores foram cortados

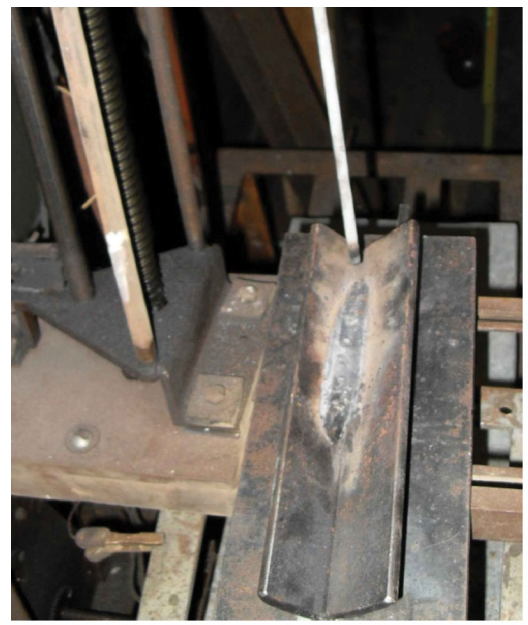

(a)

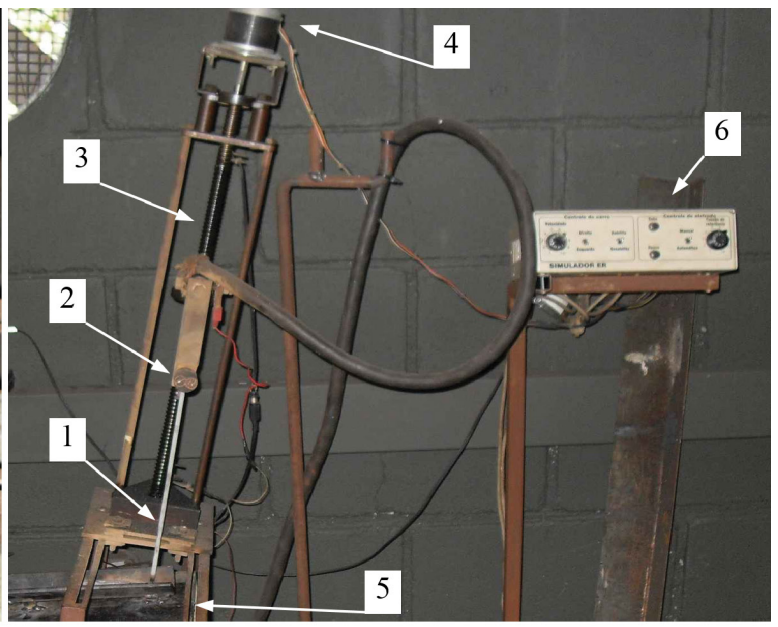

(b)

Figura 1. Aspectos da montagem experimental para soldar com eletrodo revestido: (a) Placa de teste para soldagem na posição filete plana; (b) vista geral do sistema automatizado de soldagem com eletrodo revestido, onde (1) eletrodo; (2) porta eletrodo; (3) fuso de precisão; (4) motor de passo; (5) carro para suporte da placa de teste e deslocamento longitudinal; e (6) unidade de controle de comprimento de arco e da velocidade de deslocamento longitudinal. 
Tabela 1. Condições de soldagem utilizadas para determinar a taxa de deposição e quantidade de material depositado por unidade de comprimento para cada eletrodo na corrente de $145 \mathrm{~A}$.

\begin{tabular}{cccccc}
\hline Eletrodo & $\begin{array}{c}\text { Velocidade } \\
\text { Soldagem } \\
\text { [cm/min] }\end{array}$ & Corrente [A] & $\begin{array}{c}\text { Massa } \\
\text { depositada [g] }\end{array}$ & [g/min] & Deposição \\
[g/cm]
\end{tabular}

Tabela 2. Velocidades de soldagem adotadas para cada combinação de eletrodo-corrente a fim de proporcionar o mesmo volume de cordão em soldagens comparativas.

\begin{tabular}{ccc}
\hline & \multicolumn{2}{c}{ Velocidade de Soldagem ajustada $[\mathrm{cm} / \mathrm{min}]$} \\
Eletrodo & $\mathbf{1 1 5}[\mathbf{A}]$ & $\mathbf{1 4 5}[\mathbf{A}]$ \\
\hline E7016 & 10,26 & 14,65 \\
E7018 & 10,76 & 15,37 \\
E7024 & 14,95 & 21,36 \\
\hline
\end{tabular}

cuidando-se para não se danificar o revestimento). Os diâmetros da alma e do revestimento foram medidos com um paquímetro (média de no mínimo 5 medições em locais diferentes ao longo da alma e do revestimento). A partir desses dados, foi possível calcular a área de seção transversal da alma metálica e do revestimento. Com isso, pode-se chegar também ao volume por unidade de comprimento. De posse de uma balança digital de grande resolução $(0,01 \mathrm{~g})$ e do volume do eletrodo, podem-se determinar também as densidades do eletrodo (alma e revestimento) e, por exclusão da alma por ter densidade conhecida, de cada revestimento. Além disso, foi avaliada a composição do revestimento via MEV-EDS, através de seções transversais dos eletrodos (em cortadeira metalográfica especiais e com cuidado para não danificar o revestimento).

\section{Resultados e Discussões}

O mapeamento químico dos elementos distribuídos no revestimento, obtido via MEV-EDS, mas com o acessório "mapping scan", é apresentado nas Figuras 2, 3 e 4. Como esperado, pode-se perceber a ausência de ferro no revestimento do E7016, ao contrário dos revestimentos dos demais eletrodos. O cálcio, elemento principal, seja como carbonato ou como fluoreto, que proporciona a basicidade do revestimento do eletrodo, aparece significativamente somente nos eletrodos básicos (E7016 e E7018). De forma inesperada, observou-se uma grande quantidade de titânio nos eletrodos básicos, sobretudo nos eletrodos sem pó de ferro (E7016).

As características químicas foram confirmadas pelas análises semi-quantitativas via MEV-EDS, cujos resultados estão dispostos nas Tabelas 3 e 4. Entretanto, algumas considerações devem ser feitas em relação a estes dados, sendo:

- Trata-se de análises semi-quantitativas, e os valores totais sempre somam 100\% (ou seja, pode haver inacurácias intrínsecas aos método, pois $\mathrm{O}_{2}$ entra como balanço);

- Ao se fazer uma análise química via MEV-EDS, pelo fato da área analisada ser muito pequena e restrita, pode-se ocasionar um erro de escala (para uma estimativa de representatividade do todo, seria necessário fazer a análise em várias seções/campos do eletrodo).

Sob estas considerações, os resultados devem ser tomados como orientação e não como conclusivos sobre a composição química do revestimento destes eletrodos. De qualquer forma, em função do escopo do trabalho, não se demanda uma análise quantitativa precisa, pois foi feita apenas para caracterização de cada eletrodo, evitando análises antagônicas. Mas mesmo assim pode-se destacar o baixo teor de Fe observado no eletrodo E7018, condizente com a pouca maior taxa de deposição em relação ao E7016, como mostrado na Tabela 1.

Para melhorar o conhecimento sobre os eletrodos, algumas características físicas destes também foram mensuradas e podem ser verificadas na Tabela 5. 


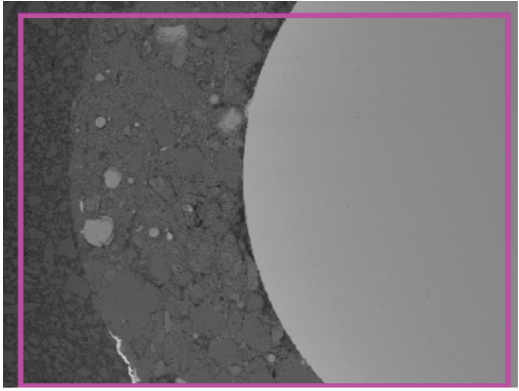

$1 \mathrm{~mm}$ (a) Electron Image 1

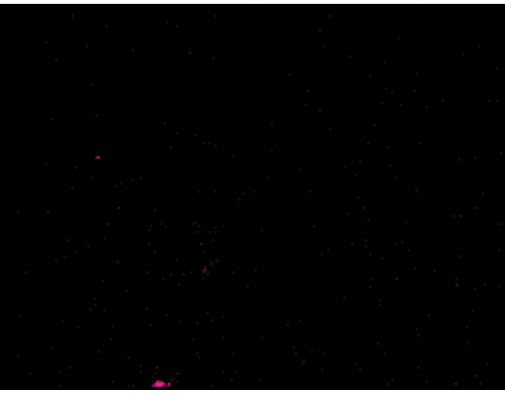

(d) Ca Kal

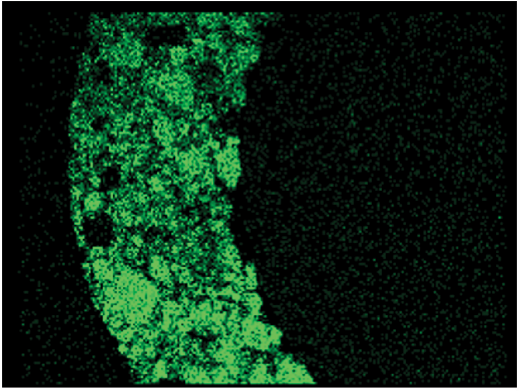

(b) Fe Ka1

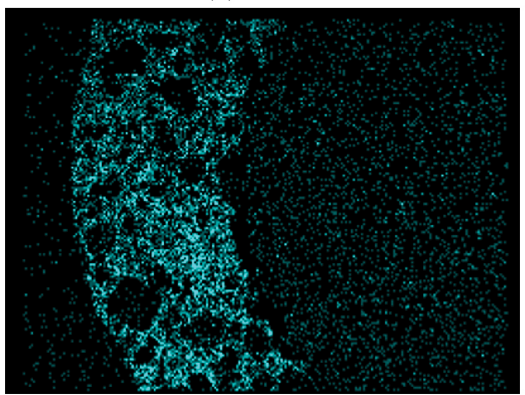

(e) Mg Ka1_2

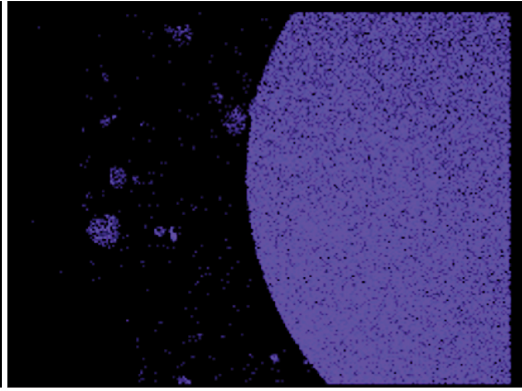

(c) Ti Kal

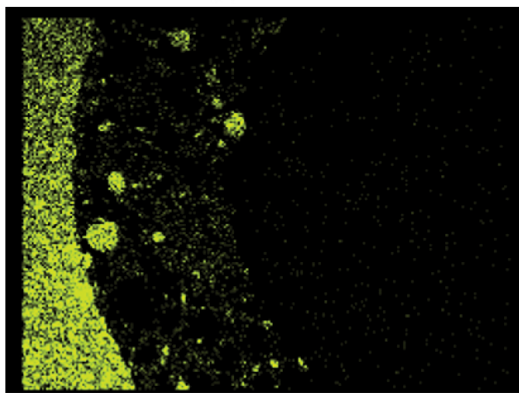

(f) Si Kal

Figura 2. Mapeamento de composição química sobre uma seção transversal do revestimento do eletrodo E7016, permitindo visualizar qualitativamente os elementos que o constituem por meio de tonalidade de cor, onde: (a) micrografia do revestimento/eletrodo como um todo; (b) Fe; (c) Ti; (d) Ca; (e) Mg; (f) Si.
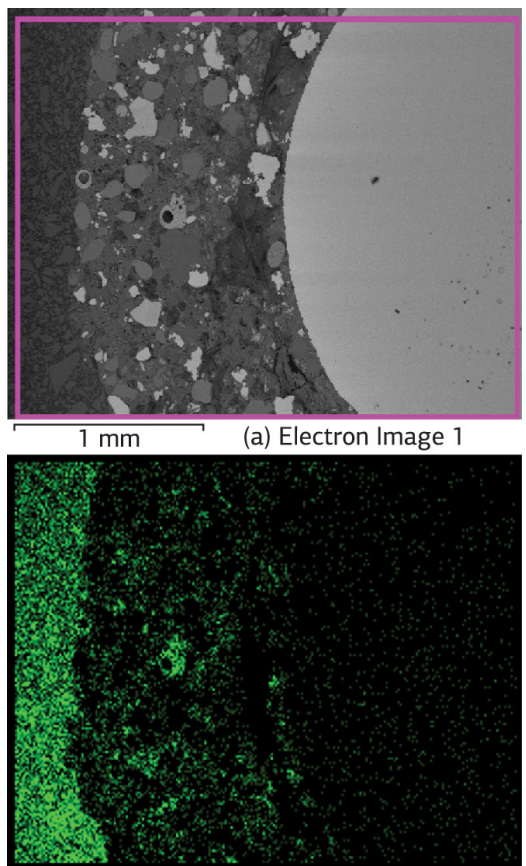

(d) Si Kal

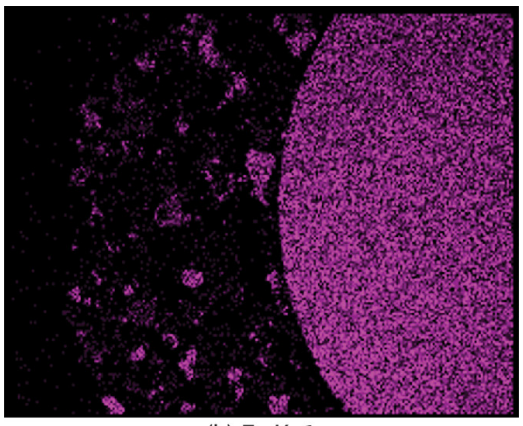

(b) Fe Ka1

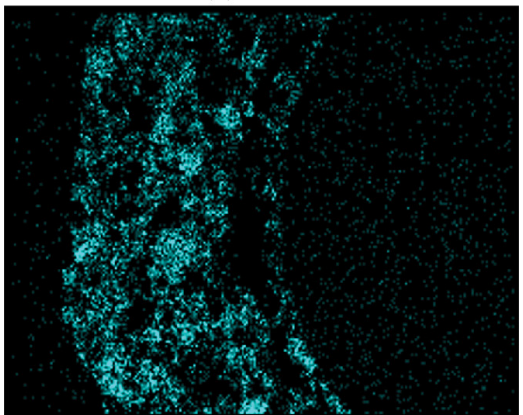

(e) Ca Ka1

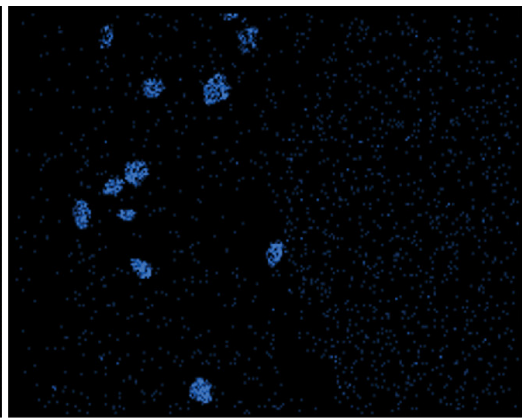

(c) Ti Kal

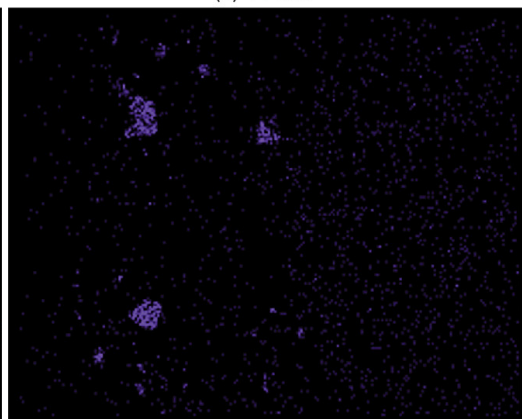

(f) $\mathrm{Mn} \mathrm{Ka1}$

Figura 3. Mapeamento de composição química sobre uma seção transversal do revestimento do eletrodo E7018, onde: (a) micrografia do revestimento/eletrodo como um todo; (b) Fe; (c) Ti; (d) - Si; (e) - Ca; (f) - Mn. 


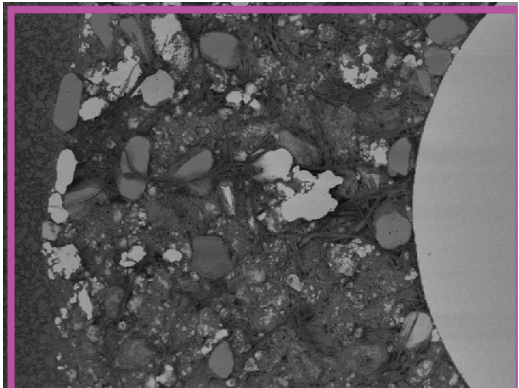

$1 \mathrm{~mm}$ (a) Electron Image 1

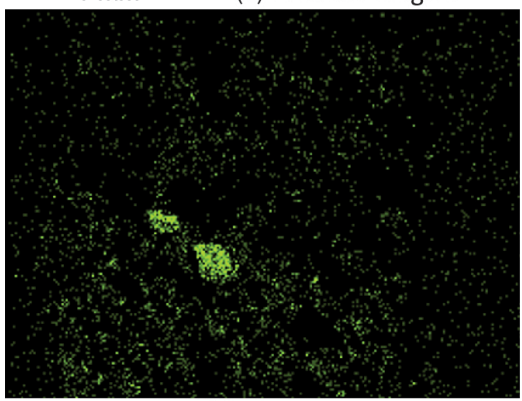

(d) Al Kal

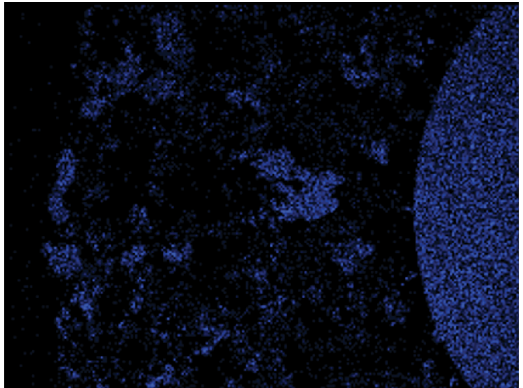

(b) Fe Kal

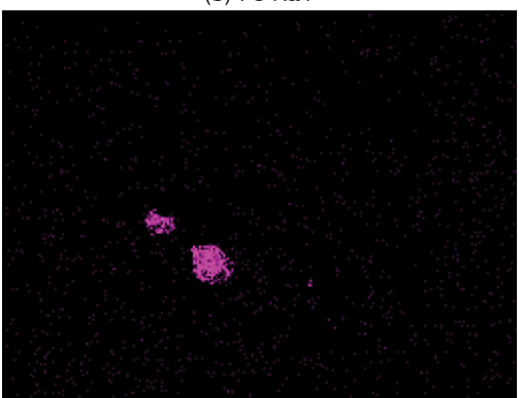

(e) Mg Ka1_2

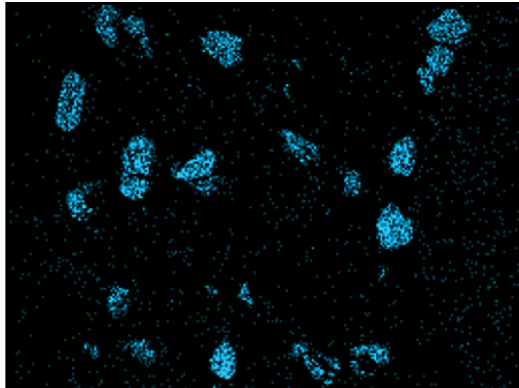

(c) Ti Kal

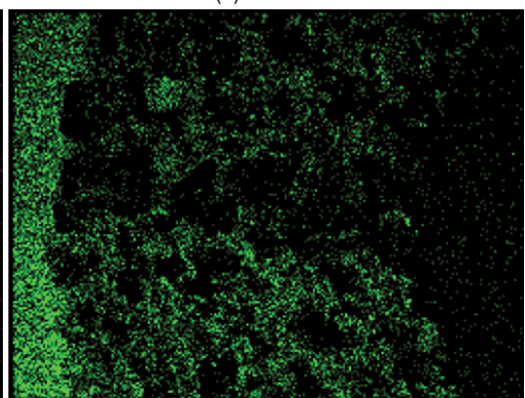

(f) Si Kal

Figura 4. Mapeamento de composição química sobre uma seção transversal do revestimento do eletrodo E7024, onde: (a) micrografia do revestimento/eletrodo como um todo; (b) Fe; (c) Ti; (d) Al; (e) Mg; (f) Si.

Tabela 3. Análise semi-quantitativa via MEV-EDS da composição química dos revestimentos dos eletrodos.

\begin{tabular}{cccccccccccccc}
\hline Eletrodo & $\mathbf{0}$ & Fe & Mn & Si & Na & Mg & Al & Ca & Ti & K & F & $\begin{array}{c}\text { Zr } \\
\text { Total } \\
\text { (\%) }\end{array}$ \\
\hline E7016 & 46,0 & 0,5 & 0,0 & 5,8 & 2,4 & 4,3 & 0,3 & 15,4 & 11,3 & 2,0 & 12,0 & 0,0 & 100,0 \\
E7018 & 26,1 & 1,9 & 3,1 & 7,9 & 1,7 & 0,0 & 0,7 & 29,1 & 3,9 & 2,1 & 23,5 & 0,0 & 100,0 \\
E7024 & 44,8 & 11,9 & 6,7 & 11,3 & 3,0 & 0,5 & 3,3 & 2,8 & 10,7 & 3,2 & 0,0 & 2,0 & 100,0 \\
\hline
\end{tabular}

Tabela 4. Análise semi-quantitativa via MEV-EDS da composição química dos revestimentos dos eletrodos, desconsiderando o teor de oxigênio.

\begin{tabular}{|c|c|c|c|c|c|c|c|c|c|c|c|c|c|}
\hline \multirow[b]{2}{*}{ Eletrodo } & \multicolumn{13}{|c|}{ Concentração em peso (\%) } \\
\hline & 0 & $\mathrm{Fe}$ & $\mathbf{M n}$ & $\mathbf{S i}$ & $\mathrm{Na}$ & Mg & Al & $\mathrm{Ca}$ & Ti & K & $\mathbf{F}$ & $\mathrm{Zr}$ & $\begin{array}{l}\text { Total } \\
\text { (\%) }\end{array}$ \\
\hline E7016 & 0,0 & 0,9 & 0,0 & 10,8 & 4,4 & 8,0 & 0,5 & 28,5 & 20,9 & 3,7 & 22,2 & 0,0 & 100,0 \\
\hline E7018 & 0,0 & 2,6 & 4,2 & 10,7 & 2,2 & 0,0 & 0,9 & 39,4 & 5,3 & 2,8 & 31,8 & 0,0 & 100,0 \\
\hline E7024 & 0,0 & 21,6 & 12,1 & 20,4 & 5,4 & 0,9 & 5,9 & 5,0 & 19,4 & 5,7 & 0,0 & 3,6 & 100,0 \\
\hline
\end{tabular}

Tabela 5. Características físicas dos eletrodos.

\begin{tabular}{|c|c|c|c|c|c|c|c|c|c|c|c|c|c|}
\hline \multirow[t]{2}{*}{ Tipo } & \multicolumn{2}{|c|}{$\begin{array}{l}\text { Diâmetro } \\
\text { [mm] }\end{array}$} & \multicolumn{3}{|c|}{$\begin{array}{l}\text { Área da seção trans- } \\
\text { versal }\left[\mathrm{mm}^{2}\right]\end{array}$} & \multicolumn{3}{|c|}{$\begin{array}{l}\text { Volume }\left[\mathrm{cm}^{3}\right] \text { por } \mathrm{cm} \\
\text { de comprimento }\end{array}$} & \multicolumn{3}{|c|}{$\begin{array}{l}\text { Massa [g] por } \mathrm{cm} \text { de } \\
\text { comprimento }\end{array}$} & \multicolumn{2}{|c|}{$\begin{array}{l}\text { Densidade } \\
{\left[\mathrm{g} / \mathrm{cm}^{3}\right]}\end{array}$} \\
\hline & Alma & Eletr. & Alma & Eletr. & Revest. & Alma & Eletr. & Revest. & Alma & Eletr. & Revest. & Alma & Revest. \\
\hline E7016 & 3,21 & 5,04 & 8,11 & 19,98 & 11,87 & 0,7 & 185 & 1,10 & 5,88 & & 2,24 & 7,83 & 2.04 \\
\hline E7018 & 3,23 & 5,55 & 8,20 & 24,20 & 16,01 & 0,77 & 2,27 & 1,50 & 6,09 & 10, & 3,92 & 7,91 & 2,61 \\
\hline E7024 & 3,24 & 6,82 & 8,22 & 36,53 & 28,30 & 0,79 & 3,49 & 2,71 & 6,18 & 15,15 & 8,98 & 7,85 & 3,32 \\
\hline
\end{tabular}


Os valores médios de corrente e tensão foram monitorados através de um sistema A/D de aquisição de sinais (2 kHz e 12 Bit) e o tratamento/visualização dos dados por uma interface dedicada confeccionada em ambiente Labview. Os dados de tensão e corrente para todos os testes estão na Tabela 6. Pela Figura 5, pode-se observar que a aquisição foi realizada abrangendo do início ao fim do processo. A discrepância entre o valor objetivado e o monitorado se deve a fonte ser eletromagnética, com regulagem por núcleo móvel, e se ter usado apenas uma regulagem para cada corrente, independentemente do eletrodo. Pela curva característica estática deste tipo de fonte ser "tombante", a corrente imposta vai depender da tensão solicitada pelo arco. A Figura 5 mostra um oscilograma típico das soldagens. Deve-se ressaltar, entretanto que a relação maior tensão de arco/menor corrente média se daria sempre caso os arcos apresentassem o mesmo regime de curto-circuito (tempo e intensidade da corrente com arco aberto e em curto), o que com certeza não foi o caso.

A Figura 6 apresenta a vista superior dos cordões obtidos (mostrando a adequabilidade do sistema automatizado de soldagem), enquanto a Figura 7 ilustra as seções transversais desses cordões. Visualmente, pode-se perceber que, como metodologicamente intencionado, os cordões possuem dimensões semelhantes. Fica claro, por outro lado, que o tipo de revestimento afeta a geometria do cordão (o E7016, por exemplo, deixa o cordão mais convexo, principalmente em menor corrente, mas é o de maior penetração). Além disto, como as maiores velocidades foram praticadas para o eletrodo E7024 (para se manter o mesmo volume de cordão), pode-se ver nitidamente pela Figura 7c e 7f que a zona afetada pelo calor (ZAC) do cordão realizado com o E7024 ficou menor do que das outras condições, mas praticamente com as mesmas dimensões de cordão. É interessante ressaltar que este comportamento se deu para os dois níveis de corrente utilizados, 115 e 145 A. As justificativas para tal, propostas pelos autores, seria devido a princípio às maiores velocidades praticadas com o eletrodo E7024, mas deve-se levar em consideração também a parte do calor necessário para fundir uma massa de revestimento substancialmente maior desse eletrodo em relação aos demais (ver Tabela 5). É interessante observar também nessa figura que a ZAC

Tabela 6. Valores médios de corrente e tensão durante as soldagens.

\begin{tabular}{cccc}
\hline Eletrodo & \multicolumn{2}{c}{ Corrente [A] } & $\begin{array}{c}\text { Tensão } \\
\text { Média [V] }\end{array}$ \\
\hline E7016 & 115 & 114,7 & 25,9 \\
E7018 & & 115,8 & 26,3 \\
E7024 & & 108,3 & 30,4 \\
E7016 & 145 & 150,5 & 23,8 \\
E7018 & & 151,8 & 27,7 \\
E7024 & & 142,0 & 32,8 \\
\hline
\end{tabular}
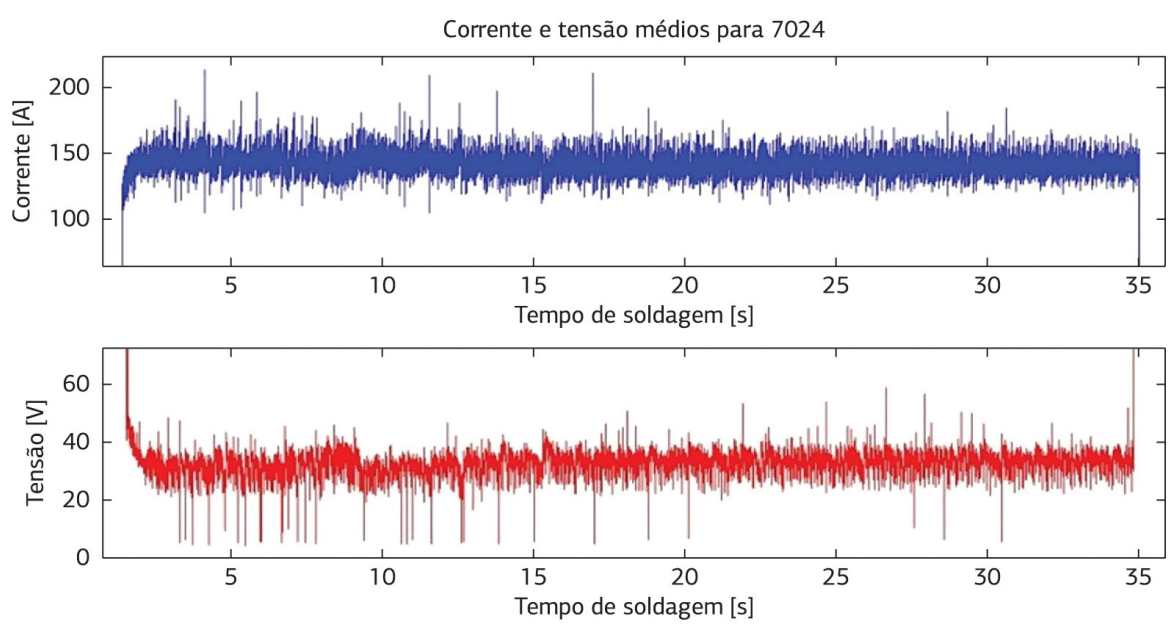

Figura 5. Oscilograma típico resultante do monitoramento de corrente e tensão (E7024, com corrente de 145 A). 


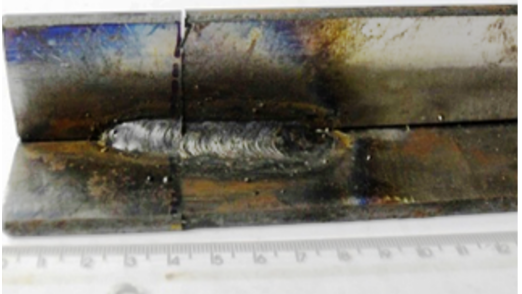

(a)

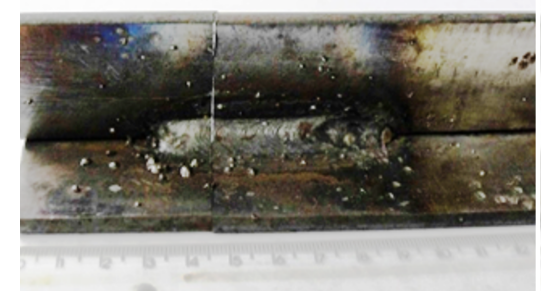

(d)

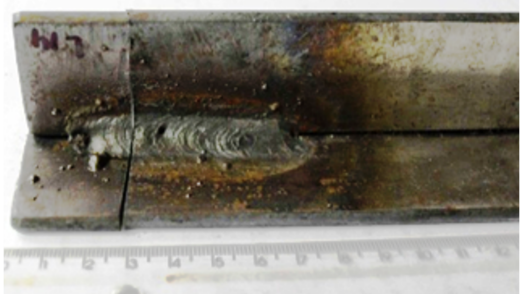

(b)

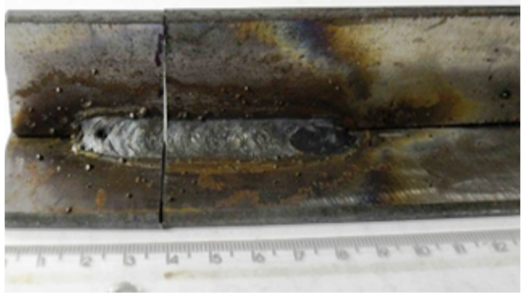

(e)

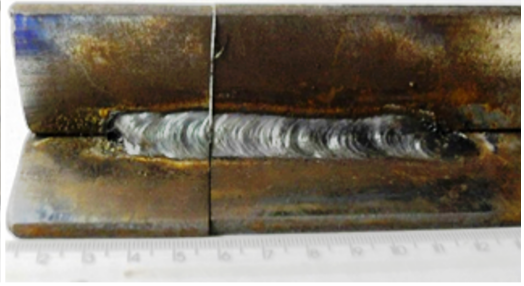

(c)

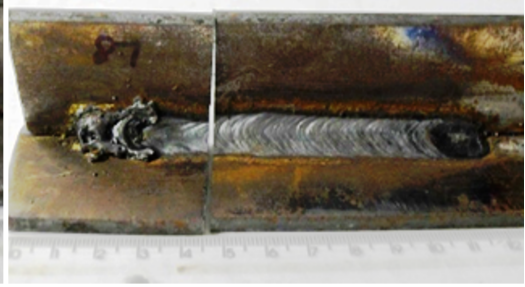

(f)

Figura 6. Cordões de solda produzidos com as combinações de corrente nominal e tipo de eletrodo (o corte indica a posição da retirada da seção transversal para macrografia), sendo: (a) 115 A (E7016); (b) 115 A (E7018); (c) 115 A (E7024); (d) 145 A (E7016); (e) 145 A (E7018); (f) 145 A (E7024).

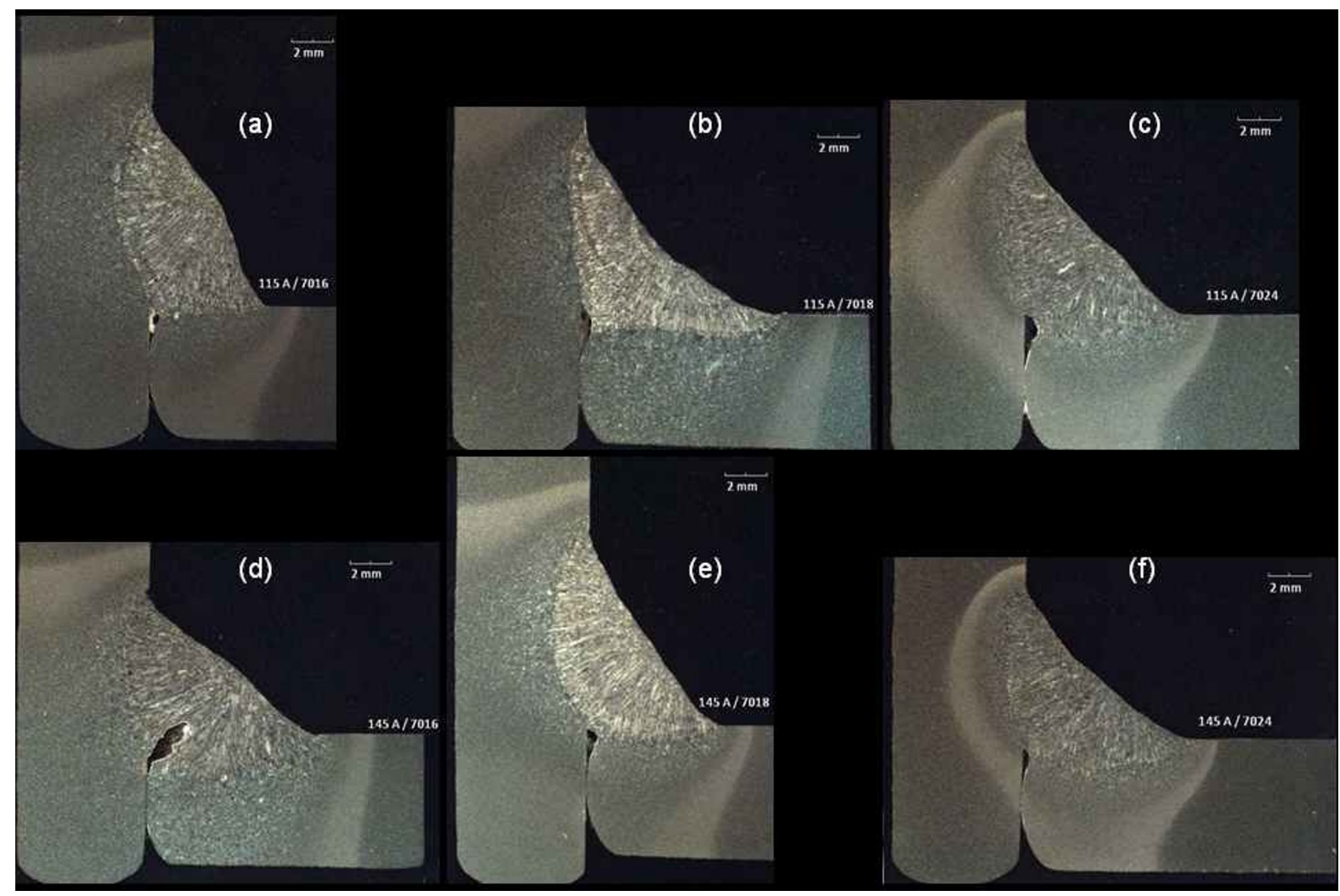

Figura 7. Seções transversais dos cordões de solda produzidos com as combinações de corrente e tipo de eletrodo, sendo: (a) 115 A (E7016); (b) 115 A (E7018); (c) 115 A (E7024); (d) 145 A (E7016); (e) 145 A (E7018); (f) 145 A (E7024). 
de uma forma geral foi maior para soldagens em menor corrente, justificável também pela menor velocidade de soldagem para os respectivos casos. Ademais, com correntes maiores tem-se proporcionalmente, menor energia de soldagem para se obter o mesmo volume de cordão, como pode ser visto pela Tabela 7. Infelizmente, a análise desses fenômenos não foram encontradas na literatura, para reforçar ou contrariar as hipóteses dos autores.

Conforme ilustrado pela Figura 8a, para todos os eletrodos houve um aumento da taxa de deposição com o aumento da corrente (cerca de $30 \%$ de incremento), o que já era esperado. As maiores taxas de deposição foram obtidas com o eletrodo E7024, vinculado ao maior teor de pó de ferro no seu revestimento. Contudo, a diferença entre o E7016 e E7018 foi pequena, mas existente, justificável pelo fato de que, de acordo com as Tabelas 3 e 4 , o eletrodo E7018, apesar de ser normalmente referenciado como de alta taxa de deposição por conter alto teor de pó de ferro no seu revestimento, não mostrou ter estas características na amostra utilizada neste trabalho. Ao considerar a taxa de fusão dos eletrodos (Figura 8b) há a mesma tendência relativa ao comportamento descrito para deposição, dado este que pode ser confirmado pelas Tabelas 8 e 9.

Tabela 7. Relação entre a corrente e a velocidade de soldagem para cada eletrodo.

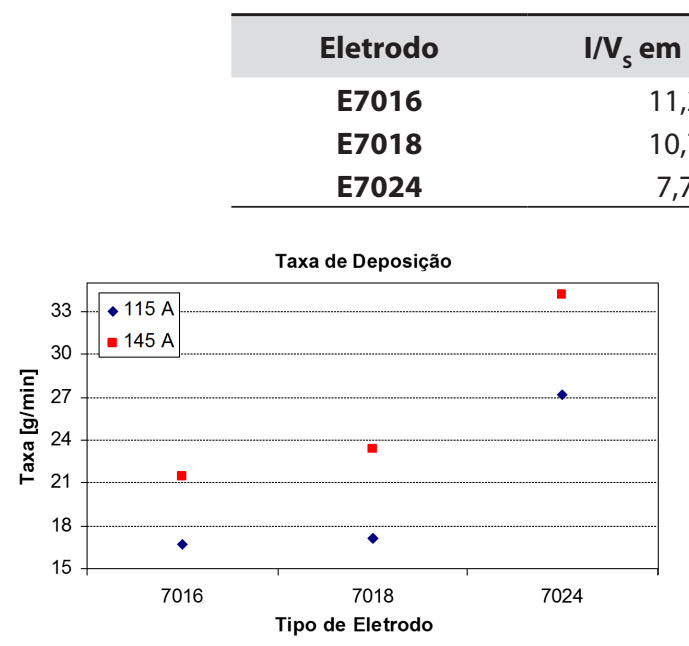

(a)

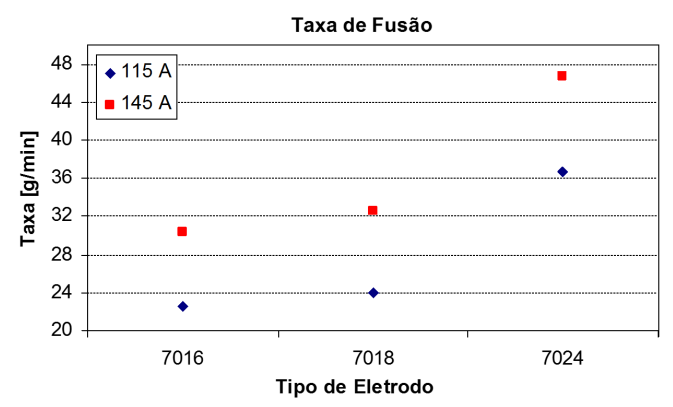

(b)

Figura 8. Efeitos da intensidade de corrente e do teor de ferro no revestimento sobre as taxas de deposição (a) e de fusão (b).

Tabela 8. Taxa de deposição para os três eletrodos nos dois níveis de corrente utilizados.

\begin{tabular}{|c|c|c|c|c|c|c|c|}
\hline \multirow[b]{2}{*}{ Eletrodo } & \multicolumn{3}{|c|}{$115 \mathrm{~A}$} & \multicolumn{3}{|c|}{$145 \mathrm{~A}$} & \multirow{2}{*}{$\begin{array}{l}\text { Relação } \\
145 / 115\end{array}$} \\
\hline & Massa [g] & Tempo [s] & Taxa [g/min] & Massa [g] & Tempo [s] & Taxa [g/min] & \\
\hline E7016 & 12,5 & 45,0 & 16,7 & 12,50 & 35,0 & 21,4 & $+29 \%$ \\
\hline E7018 & 12,8 & 45,0 & 17,1 & 13,61 & 35,0 & 23,3 & $+36 \%$ \\
\hline E7024 & 20,4 & 45,0 & 27,2 & 19,93 & 35,0 & 34,2 & $+25 \%$ \\
\hline \multicolumn{3}{|c|}{ Incremento E7018/E7016 } & $+2 \%$ & & & $+9 \%$ & \\
\hline \multicolumn{3}{|c|}{ Incremento E7024/E7016 } & $+63 \%$ & & & $+60 \%$ & \\
\hline
\end{tabular}

Tabela 9. Taxa de fusão para os três eletrodos nos dois níveis de corrente utilizados.

\begin{tabular}{|c|c|c|c|c|c|c|c|}
\hline \multirow[b]{2}{*}{ Eletrodo } & \multicolumn{3}{|c|}{$115 \mathrm{~A}$} & \multicolumn{3}{|c|}{$145 \mathrm{~A}$} & \multirow{2}{*}{$\begin{array}{l}\text { Relação } \\
145 / 115\end{array}$} \\
\hline & Massa [g] & Tempo [s] & Taxa [g/min] & Massa [g] & Tempo [s] & Taxa [g/min] & \\
\hline E7016 & 16,94 & 45,0 & 22,6 & 17,65 & 35,0 & 30,3 & $+34 \%$ \\
\hline E7018 & 18,02 & 45,0 & 24,0 & 19,02 & 35,0 & 32,6 & $+36 \%$ \\
\hline E7024 & 27,52 & 45,0 & 36,7 & 27,22 & 35,0 & 46,7 & $+27 \%$ \\
\hline \multicolumn{3}{|c|}{ Incremento E7018/E7016 } & $+6 \%$ & & & $+8 \%$ & \\
\hline \multicolumn{3}{|c|}{ Incremento E7024/E7016 } & $+62 \%$ & & & $+54 \%$ & \\
\hline
\end{tabular}


Importante ressaltar que, como mostra a Tabela 8 para a corrente de $115 \mathrm{~A}$, um pequeno incremento de pouco mais de 1,5\% do teor de Fe no revestimento do E7018 em relação ao E7016 (ver Tabela 3) fez a taxa de deposição do eletrodo aumentar de $2 \%$ a $9 \%$, com certa dependência da corrente. Já quando o teor de Fe no revestimento aumentou em cerca de 11,5\%, comparando o E7024 em relação ao E7016, o aumento da taxa de deposição foi bem mais significativo (cerca de 60\%), mas passou a ser independente da corrente. Estes resultados sugerem que a adição de pó de ferro tem um papel governante no aumento da taxa de deposição, mas o aumento em torno de $30 \%$ na taxa de fusão ao passar a corrente de 115 para 145 A mostra que qualquer aumento da corrente é também significante. Assim, pode-se dizer que ambos os fatores sejam importantes, mas a adição de pó de ferro é predominante.

\section{Conclusão}

Considerando o objetivo de avaliar o papel do pó de ferro frente ao da corrente sobre o mecanismo de fusão e deposição de eletrodos revestidos, conclui-se que a taxa de fusão, e consequentemente a de deposição, são aumentadas tanto pelo aumento do teor de pó de ferro no revestimento como por uma maior capacidade nominal de condução de corrente pelo eletrodo. O pó de ferro no revestimento demanda menos energia do que o aço maciço da alma para se fundir e se incorporar como metal de solda. Portanto, com uma mesma corrente, quanto maior o conteúdo de pó de ferro no revestimento, maior a taxa de fusão do eletrodo. Mas, o pó de ferro no revestimento, adicionalmente, aumenta a capacidade nominal de condução de corrente do eletrodo. Como quanto maior a corrente, maior a taxa de fusão, a capacidade de condução de corrente de um eletrodo é um fator adicional, mas não primordial, de aumento da taxa de fusão dos eletrodos revestidos.

\section{Agradecimentos}

À disponibilização dos recursos pelo Laprosolda (Centro para Pesquisa e Desenvolvimento de Processos de Soldagem) da Universidade Federal de Uberlândia, que permitiram o desenvolvimento e direcionamento do estudo.

\section{Referências}

[1] Liu S. Arc welding consumables: covered and cored electrodes - A century of evolution. In: International Conference on Trends in Welding Research; 1998 June 1-5; Pine Mountain, Georgia. Pine Mountain: ASM Intl./AWS; 1999. p. 505-516.

[2] Van Den Berg RWA, Haverhals J. Advantages of high efficiency MMA electrodes. Metal Construction. 1987;19:643-644.

[3] Subramanian VR. Metal powders in manual metal arc welding electrode coatings. Indian Welding Journal. 1981;13(2):53-59.

[4] Cruz-Crespo A, Fuentes RF, Scotti A. The influence of calcite, fluorite and rutile on the fusion-related behaviour of metal cored coated electrodes for hardfacing. Journal of Materials Engineering and Performance. 2010;19(5):685-692. http:// dx.doi.org/10.1007/s11665-009-9543-2.
[5] Scotti A, Dutra JC. Influence of coating composition on performance of basic electrodes; effect of the type of iron powder. In: Proceedings of the 8th International Conference on Offshore Mechanics and Arctic Engineering; 1989 March 19-23; The Hague, Holland. The Hague: ASTM; 1989, p. 511-515.

[6] Ponomarev V, Scotti A, Miranda HC, Costa AV. Influence of the power source dynamic characteristics on the metal transfer mixed mode. Copenhagen: IIW; 2002. (International Institute of Welding Document, n. SG-212-1014-02).

[7] Grong O, Olson DL, Christensen N. Carbon oxidation in hyperbaric MMA welding. Metal Construction. 1985;17(12):810R-814R. 